\title{
Electrocardiographic intricacies clarified by echocardiography-Should the electrocardiogram be interpreted echocardiographically?
}

\author{
James $\operatorname{Ker}^{*}$ \\ Department of Physiology, University of Pretoria, Pretoria, South Africa, PO Box 24318, Gesina, Pretoria, 0031 South Africa
}

\section{A R T I C L E I N F O}

\section{Article history:}

Received 21 December 2010

Accepted 14 January 2011

Available online $\mathrm{xxxx}$

\section{Keywords:}

Electrocardiogram

Variants

Mimic

Echocardiography

\begin{abstract}
A B S T R A C T
Background: During the past century the electrocardiogram (ECG) has established itself as an integral part of the cardiovascular examination. Since the first direct recordings of cardiac potentials by Waller in 1887, to the invention of the string galvanometer by Willem Einthoven in 1901, to use in the clinic by 1910, the electrocardiogram has become the most widely used clinical tool in the diagnosis of virtually every type of heart disease. Currently up to 20 million ECGs are performed annually in the United States alone.

Hypothesis: However, in this era of readily available echocardiography, an important caveat in the interpretation of the electrocardiogram has emerged: variants of intracardiac structures which might mimic disease on the ECG.

Methods: In this perspective various structural variants of intracardiac structures, specifically variants of papillary muscles and subaortic muscular bands, will be shown, together with their associated electrocardiographic changes, mimicking disease.

Conclusion: It is concluded that in this era of readily available echocardiography, the electrocardiogram should be interpreted echocardiographically in instances where intricate variations are seen on the surface electrocardiogram. (c) 2011 Elsevier Ireland Ltd. All rights reserved.
\end{abstract}

\section{Introduction}

During the past century the electrocardiogram (ECG) has established itself as an integral part of the cardiovascular examination. Since the first direct recordings of cardiac potentials by Waller in 1887, to the invention of the string galvanometer by Willem Einthoven in 1901, to use in the clinic by 1910, the electrocardiogram has become the most widely used clinical tool in the diagnosis of virtually every type of heart disease [1].

Currently up to 20 million ECGs are performed annually in the United States alone [1].

However, in this era of readily available echocardiography, an important caveat in the interpretation of the electrocardiogram has emerged: variants of intracardiac structures which might mimic disease on the ECG.

In this perspective various structural variants of intracardiac structures will be shown, together with their associated electrocardiographic aberrations, mimicking disease.

\section{Subaortic tendon induced ST-segment elevation}

Fig. 1 is the 12-lead electrocardiogram of a 34-year old, healthy caucasian male. Note the striking ST-segment elevation in leads V3

\footnotetext{
* Tel.: +27 12 3430078; fax: +27 123430079 .

E-mail address: jker@wol.co.za.
}

and V4. The differential diagnosis of ST-segment elevation is wide and diverse and includes the following [2]: myocardial ischemia or infarction, Prinzmetal angina pattern, Takotsubo cardiomyopathy, ventricular aneurysm, pericarditis, early repolarisation pattern, left ventricular hypertrophy, left bundle branch block, other causes of myocardial injury, such as myocarditis, trauma or a tumor invading the left ventricle, hypothermia, after DC cardioversion, hyperkalemia, hypercalcemia, type $1 \mathrm{C}$ antiarrhythmic drugs, intracranial hemorrhage and the Brugada pattern. In this particular case none of the above were present and the only explanation found was the presence of a peculiar muscular band, extending between the interventricular septum and the left ventricular apex [2] (Fig. 2). The characteristics of this peculiar subaortic muscular band have been described before [3]. The possible pathophysiological mechanisms of this phenomenon of subaortic tendon induced ST-segment elevation have been described in detail [2].

\section{Solitary papillary muscle hypertrophy with QRS-and ST-segment changes}

Fig. 3 is the 12-lead electrocardiogram of a healthy 20-year old, caucasian male. Note the notching of the ascending limb of the QRScomplex in lead V4, together with ST-segment elevation and a prominent, positive U wave, also in lead V4. Echocardiography revealed isolated hypertrophy of the anterolateral papillary muscle (Fig. 4). Isolated papillary muscle hypertrophy is a rare entity and in 


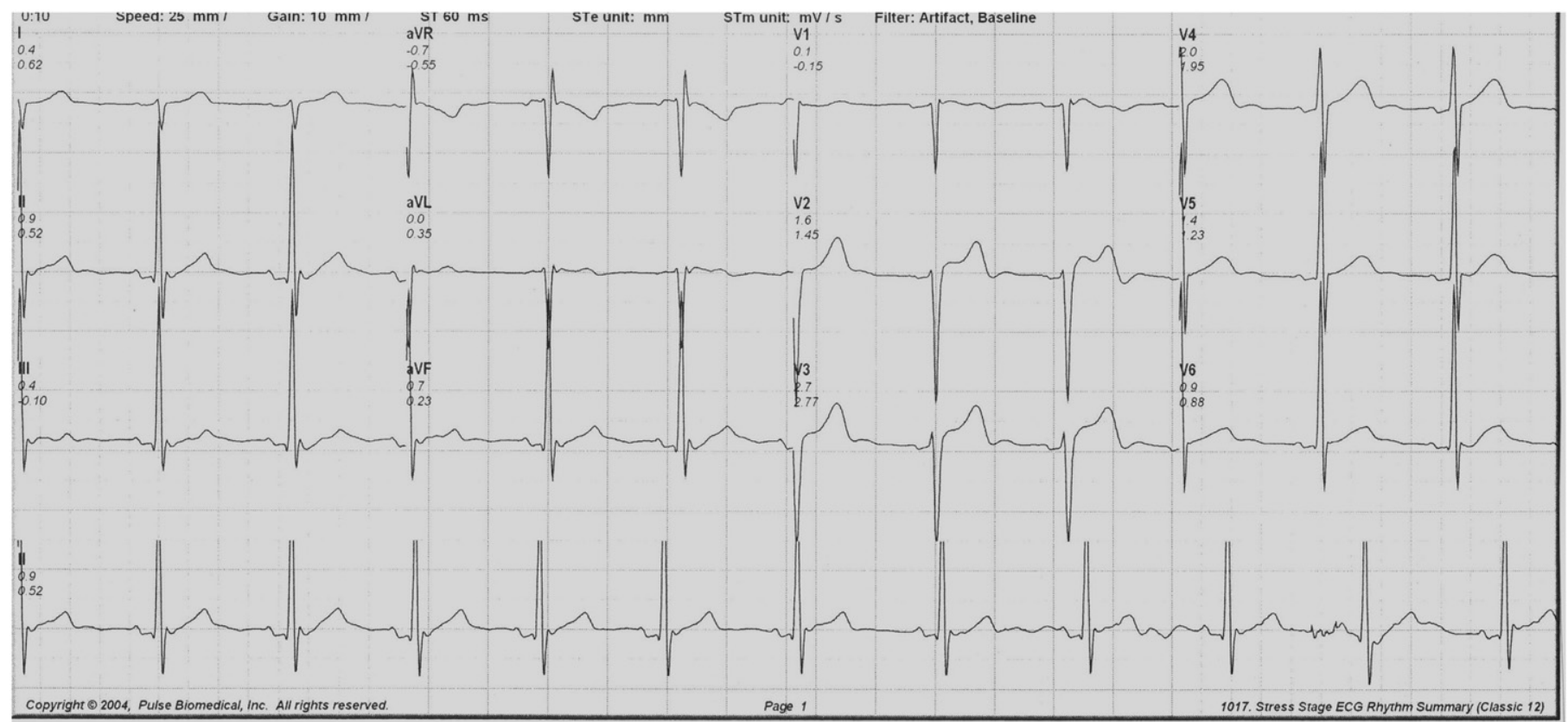

Fig. 1. 12-lead electrocardiogram of a healthy 34-year old Caucasian male. Note the ST-segment elevation in leads V3 and V4.

this case it was proposed that isolated hypertrophy of the anterolateral papillary muscle with notching of the ascending limb of the QRS complex, with ST-segment elevation and a prominent, positive U wave, all in lead V4 is a new echo-electrocardiographic syndrome [4].

\section{Papillary muscle variants and the $U$ wave}

One of the earliest hypotheses on the origin of the $U$ wave involved repolarisation of the papillary muscles and their neighboring structures [5]. Today the $U$ wave is still an electrocardiographic deflection of enigmatic origin with none of the current theories on the genesis of the $U$ wave accepted as factual. These theories include the following [5]: repolarisation of the papillary muscles, repolarisation of the Purkinje fibers outlasting that of the contracting myocardium, prolonged repolarisation in cells of the mid-myocardium-the " $\mathrm{M}$ cells", and the so-called "mechano-electrical feedback hypothesis"after-potentials, caused by mechanical forces in the ventricular wall with termination of mechanical systole.

Fig. 5 is the 12-lead electrocardiogram of a healthy 15-year old caucasian girl. Note the prominent $\mathrm{U}$ waves in the inferior leads (II, III and aVF). The only anomaly found in this case was the presence of two prominent, accessory papillary muscles (Fig. 6). Fig. 6 is the echocardiographic image demonstrating this accessory papillary muscles (marked with + ). In this case it was proposed that the prominent inferior $U$ waves are caused by the presence of the

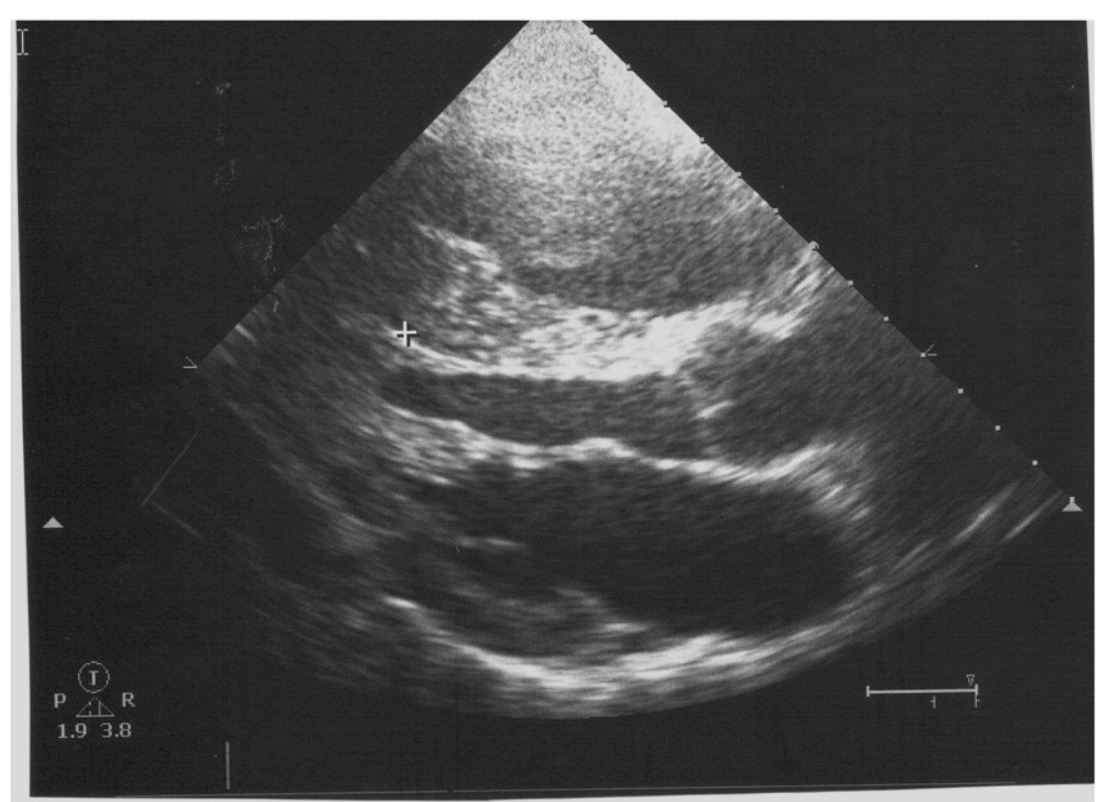

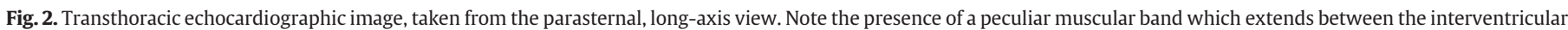
septum and the left ventricular apex. 


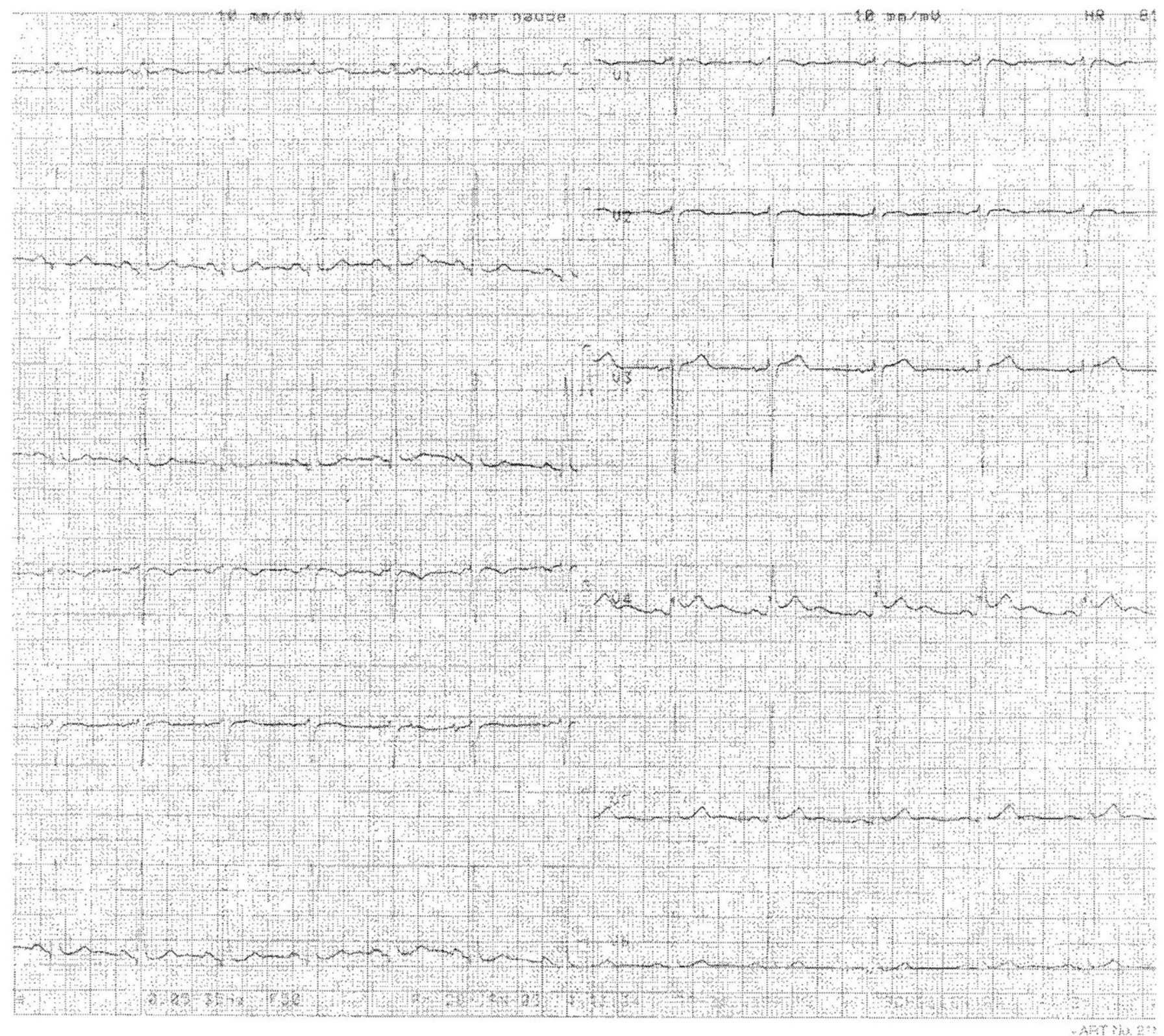

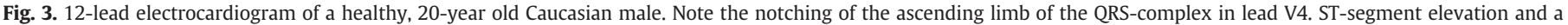
prominent, positive $\mathrm{U}$ wave are also present in lead V4.

accessory papillary muscles and the pathophysiological mechanisms were discussed [5].

Currently, there is a new focus on the morphology of the $U$ wave [6]. Usually $U$ waves are upright, $<1 \mathrm{~mm}$ in amplitude and of similar polarity than that of the preceding $T$ wave [7]. The first report of "notched" or "bifid" U waves was recently described [7]. Until this report only $\mathrm{T}$ wave bifidity has been described.

\section{Accessory papillary muscles and the double $U$ wave}

Fig. 7 is a 12-lead electrocardiogram which clearly demonstrates the presence of double $U$ waves. A recent retrospective analysis identified 3 cases of double $U$ waves in a database of 4729 patients [6]. In all three these cases of double $U$ waves, an accessory papillary muscle was clearly demonstrated [6]. Fig. 8 is an echocardiographic image, taken from the patient in Fig. 7. This is a transverse section of the left ventricle, demonstrating two accessory papillary musclesone in the 7 o'clock position and the other one just before the 3 o'clock position. Fig. 9 is a longitudinal section of the left ventricle, demonstrating the same accessory papillary muscles in another plane (marked with + ). It is proposed that the double $U$ wave is a newly observed electrocardiographic entity which is possibly and most probably the result of an accessory papillary muscle [6].

\section{Bigeminy and the bifid papillary muscle}

Fig. 10 is the 12-lead electrocardiogram of a 51 -year old Italian woman, presenting with ventricular bigeminy. After a comprehensive evaluation the only explanation found for the electrocardiographic abnormality was the presence of a peculiar structural variant of the anterolateral papillary muscle-the "bifid" papillary muscle (Fig. 11) [8].

It was recently realized that the papillary muscles of the left ventricle may be the source of frequent premature ventricular complexes $[9,10]$. Doppalapudi et al. [9] recently described a distinct new syndrome of ventricular arrhythmia arising from the base of the 


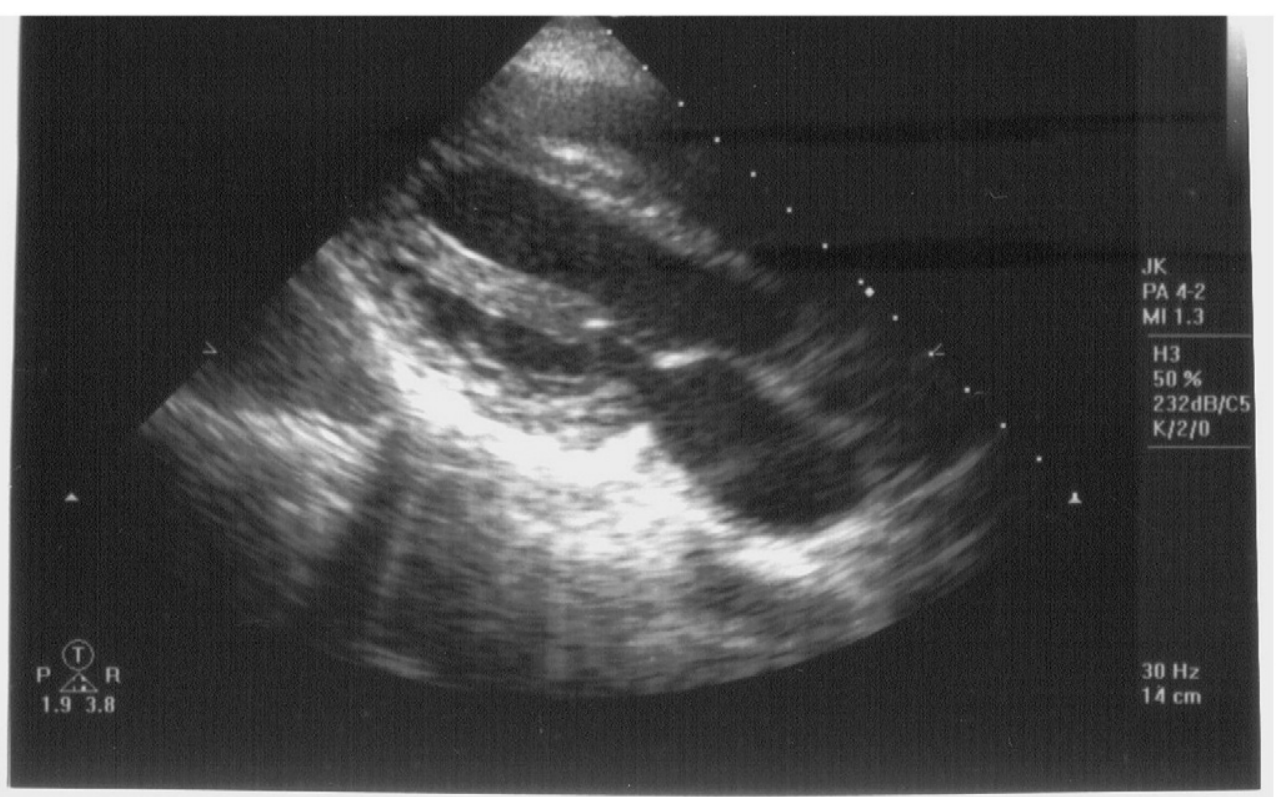

Fig. 4. Transthoracic echocardiographic image, taken from the parasternal, long-axis view. Note the isolated hypertrophy of the anterolateral papillary muscle.

posterior papillary muscle, presenting clinically as sustained ventricular tachycardia in two patients and as frequent premature ventricular complexes with salvos of non-sustained ventricular tachycardia in another five patients. This report added to the two already cited reports of the left ventricular papillary muscle(s) as the source of ventricular arrhythmia [8].

\section{Conclusion}

The papillary muscles have already been identified as potential sites of reentry, contributing to the maintenance of ventricular fibrillation in animal models [11]. Recently, the left ventricular papillary muscles have been shown to be arrhythmogenic in the human heart after myocardial infarction [11-13]. In addition to this papillary muscle arrhythmogenic entity as a complication of structural heart disease, idiopathic ventricular arrhythmia, originating from the posterior papillary muscle has also been described as a novel clinical syndrome [9]. In addition to this a distinct subgroup of idiopathic ventricular arrhythmias, arising from the anterior papillary muscle has also been described [11]. Both the anterior and posterior papillary muscles have thus been shown to be the source of ventricular arrhythmias in the human heart, without any underlying structural heart disease. The left ventricular papillary muscles are conical projections of myocardium into the left ventricular cavity, covered by endothelium [14]. A peripheral Purkinje network extends on to the surface of the papillary muscles and may serve as either a focal point of origin of arrhythmia or it may form part of a macroreentrant circuit [14].

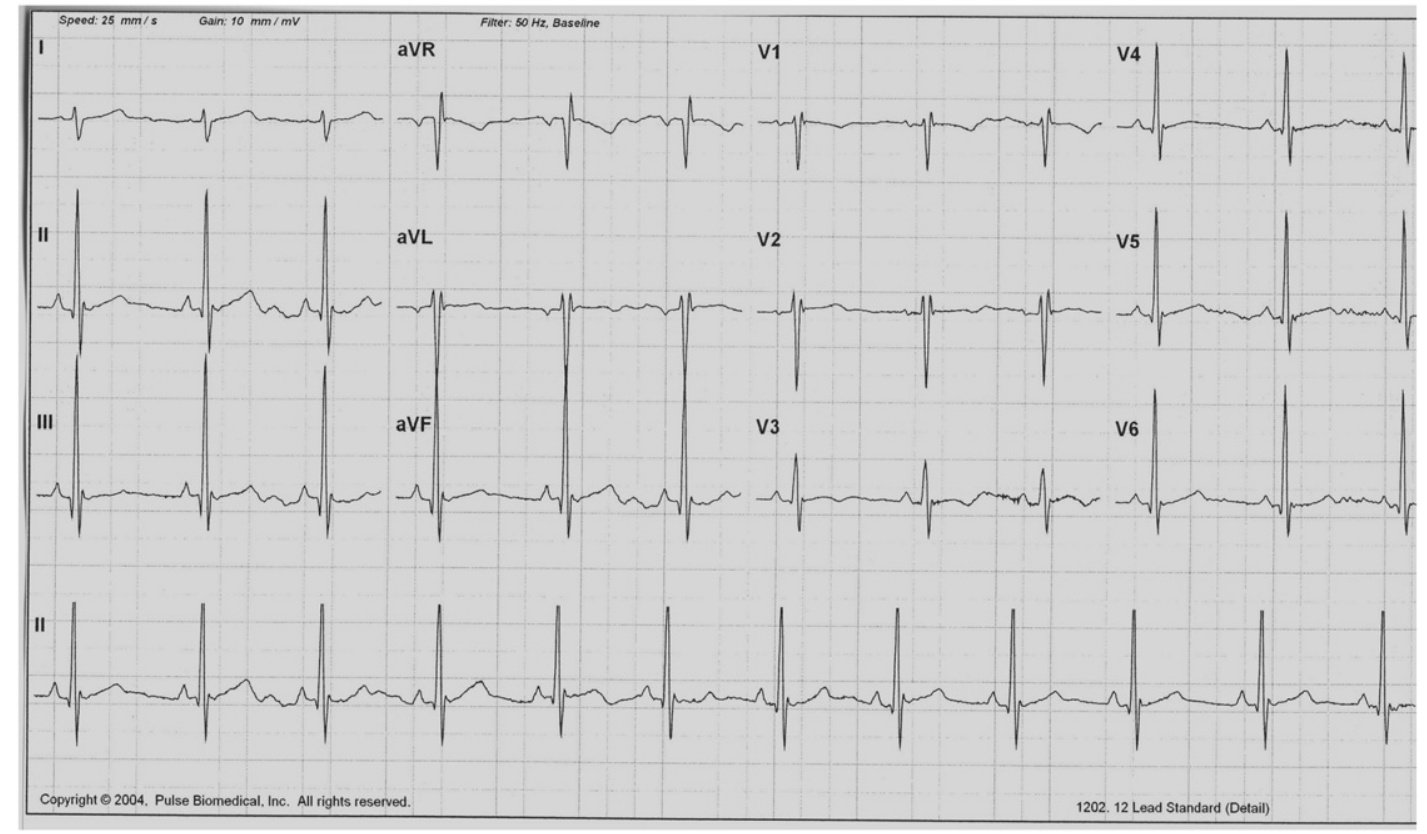

Fig. 5. 12-lead electrocardiogram of a healthy 15-year old Caucasian girl. Note the prominent U waves in the inferior leads (II, III and aVF). 


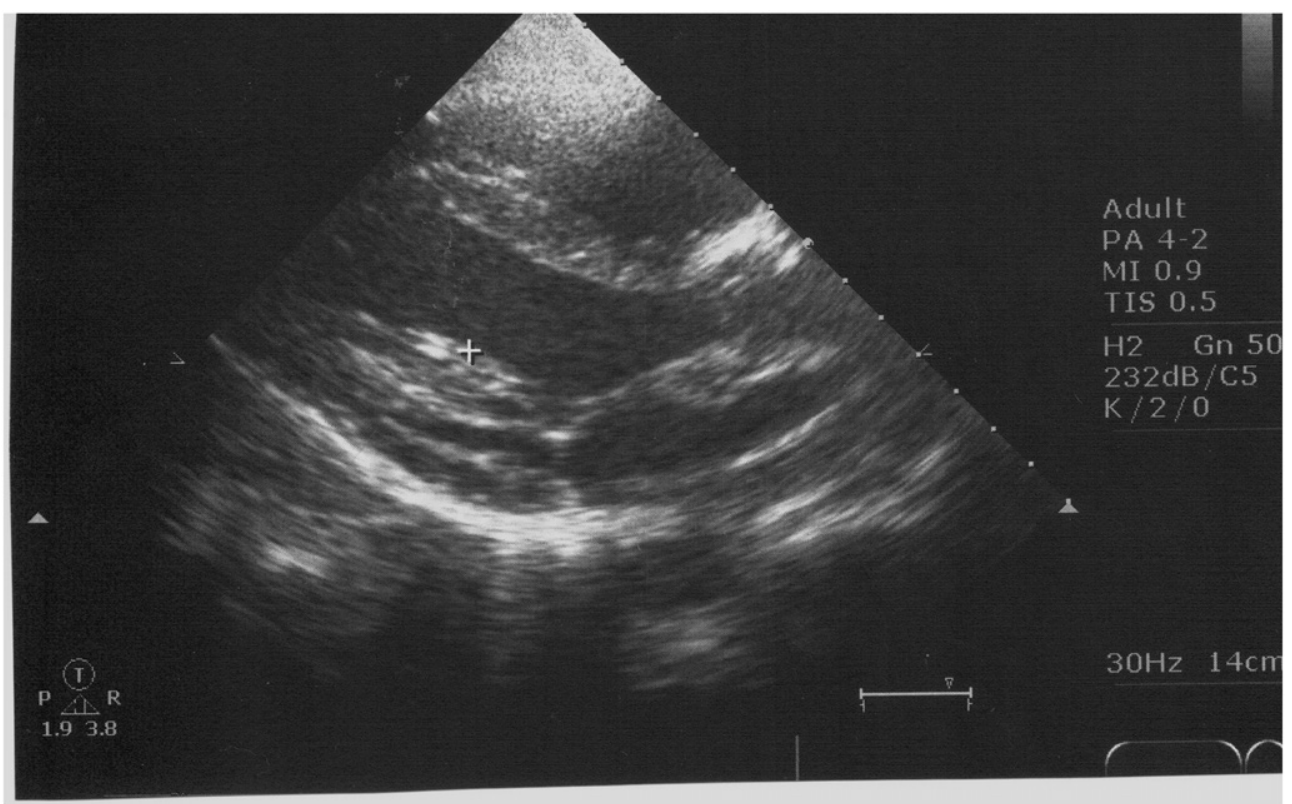

Fig. 6. Note the two prominent, accessory papillary muscles, marked with + .

In this perspective, various variants of the left ventricular papillary muscles, together with their associated electrocardiographic changes were demonstrated.

As discussed, the left ventricular papillary muscles have emerged as established role players in ventricular arrhythmias and as echocardiography is an established and excellent clinical tool to evaluate the structure, number and position of papillary muscles, it is proposed that the electrocardiogram should be interpreted according to structural data given by the echocardiogram.

\section{Competing interests}

The author declares that no competing interests are present.

\section{Acknowledgements}

The author declares that he complied with the ethical principles of publishing of the International Journal of Cardiology [15].

\section{References}

[1] Mirvis DM, Goldberger AL. Electrocardiography. In: Libby P, Bonow RO, Mann DL, Zipes DP, editors. Braunwald's heart disease. a textbook of cardiovascular medicine. eighth edition. Saunders: Elsevier; 2008.

[2] Ker J. Subaortic tendon induced ST-segment elevation-a new echo-electrocardiographic phenomenon? Cardiovasc Ultrasound 2009;7:13.

[3] Ker J. Subaortic (type 6) muscular band-innocent bystander or pathologic structure? Clin Med Insights Cardiol 2010;4:69-71.

[4] Ker J. Solitary papillary muscle hypertrophy: a new echo-electrocardiographic syndrome? Angiology 2007;58(4):502-3.

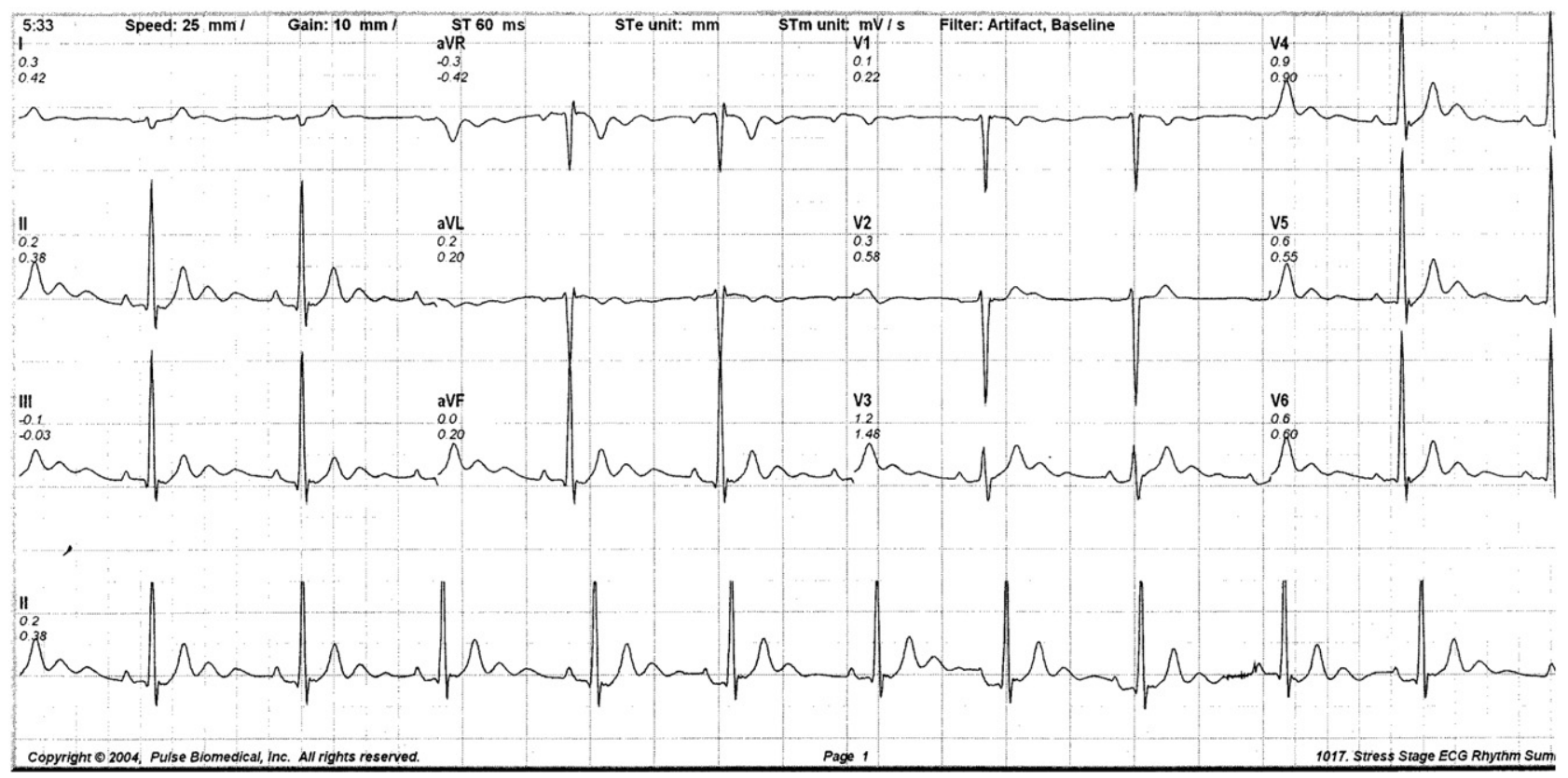

Fig. 7. 12-lead electrocardiogram. Note the presence of double U waves. 


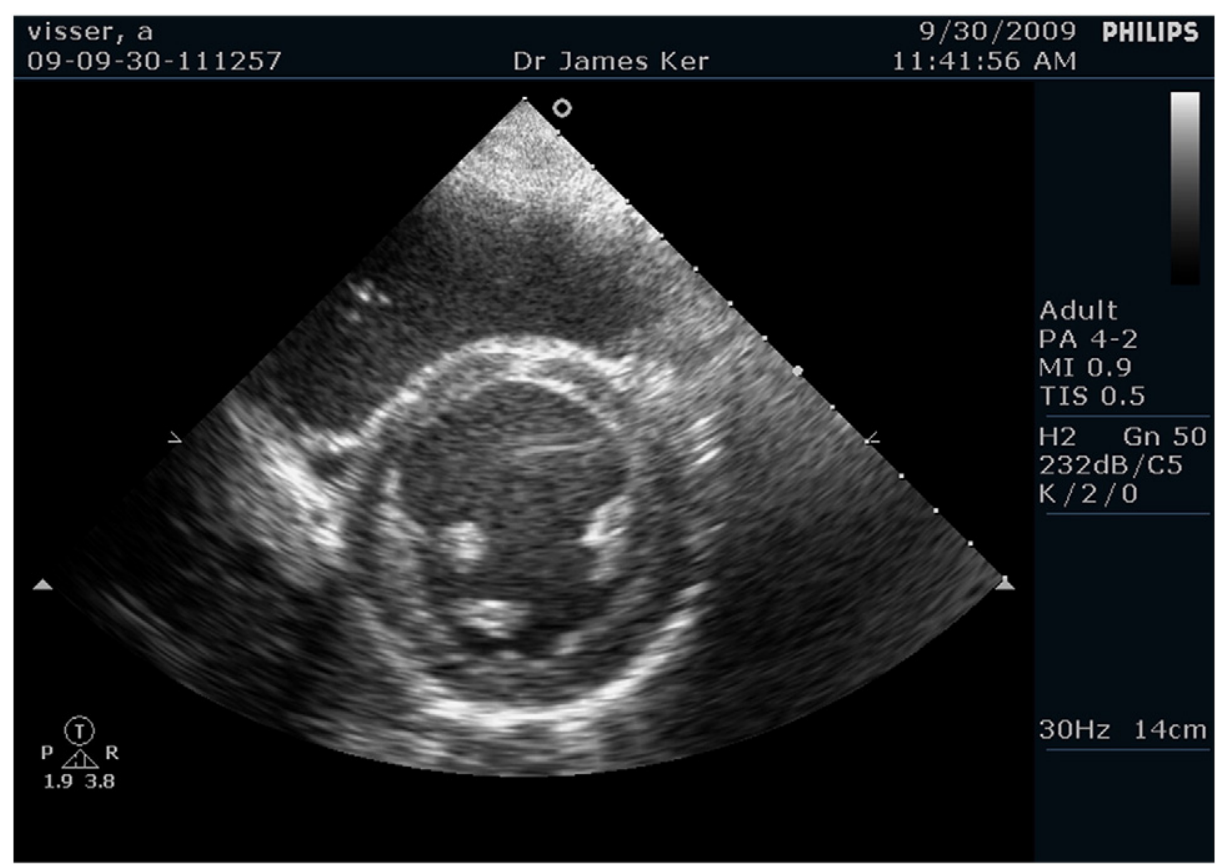

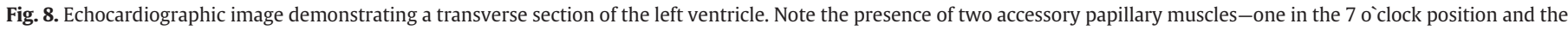
other one just before the 3 o'clock position.

[5] Ker J. The U wave and papillary muscle variants: revisiting an old association. Cardiovasc J Afr 2009;20:256-7.

[6] Ker J. The double U wave-should the electrocardiogram be interpreted echocardiographically? Clin Med Insights Cardiol 2010;4:77-83.

[7] Ariyarajah V, Khadem A, Spodick DH. Can U waves be "notched"? Ann Noninvasive Electrocardiol 2008;13(4):426-8.

[8] Ker J. Bigeminy and the bifid papillary muscle. Cardiovasc Ultrasound 2010;8: 13-4.

[9] Doppalapudi H, Yamada T, McElderry T, Plumb VJ, Epstein AE, Kay GN. Ventricular tachycardia originating from the posterior papillary muscle in the left ventricle-a novel clinical syndrome. Circ Arrhythmia Electrophysiol 2008;1:23-9.

[10] Sternick EB, Correa F, Negri R, Scarpelli RB, Gerken LM. Reversible cardiomyopathy provoked by focal ventricular arrhythmia originating from the base of the posterior papillary muscle. J Interv Electrophysiol 2009;25: 67-72.
[11] Yamada T, McElderry HT, Okada T, et al. Idiopathic focal ventricular arrhythmias originating from the anterior papillary muscle in the left ventricle. J Cardiovasc Electrophysiol 2009;20:866-72.

[12] Bogun F, Desjardins B, Crawford T, et al. Post-infarction ventricular arrhythmias originating in papillary muscles. J Am Coll Cardiol 2008;51:1794-802.

[13] Liu XK, Barrett R, Packer DL, Asirvatham SJ. Successful management of recurrent ventricular tachycardia by electrical isolation of anterolateral papillary muscle. Heart Rhythm 2008;5:479-82.

[14] Yamada T, Doppalapudi H, McElderry HT, et al. Idiopathic ventricular arrhythmias originating from the papillary muscles in the left ventricle: prevalence, electrocardiographic and electrophysiological characteristics and results of the radiofrequency catheter ablation. J Cardiovasc Electrophysiol 2010;21:62-9.

[15] Shewan LG, Coats AJ. Ethics in the authorship and publishing of scientific articles. Int J Cardiol 2010;144:1-2.

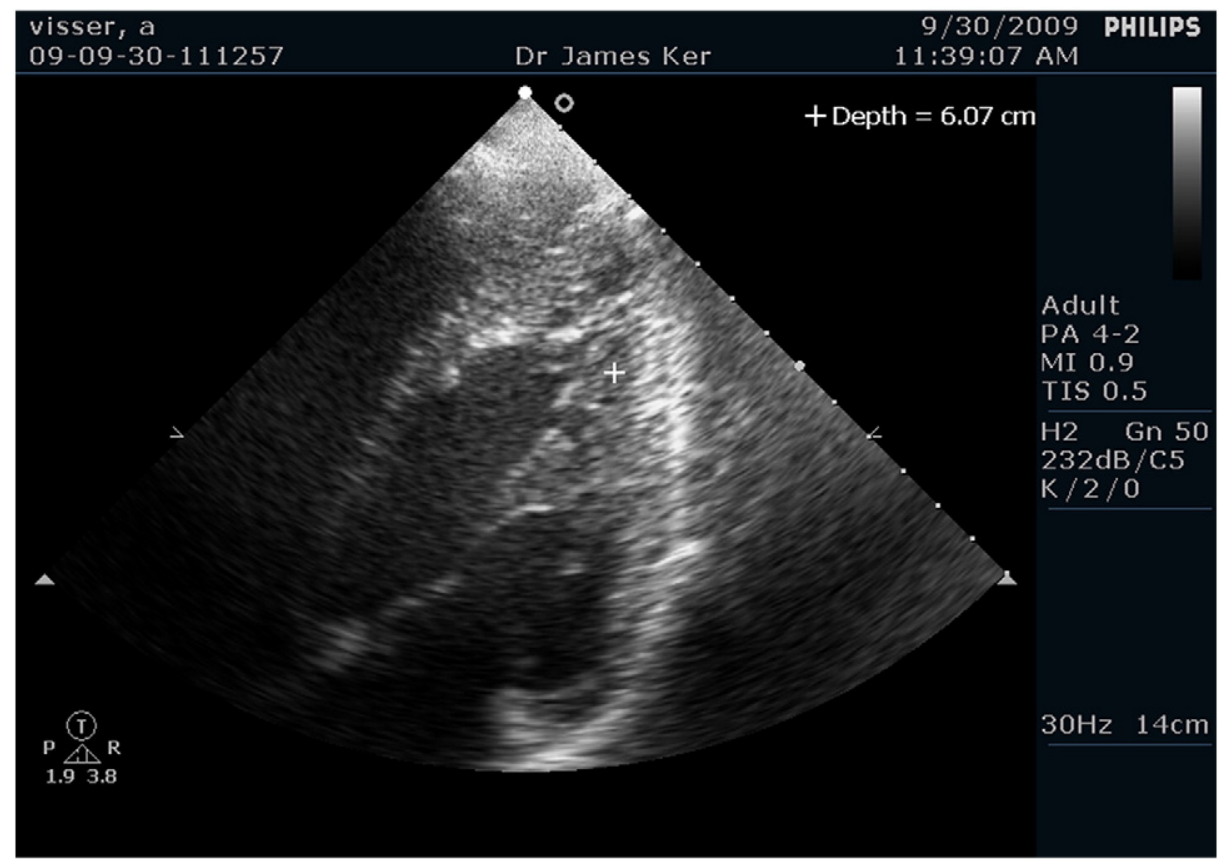

Fig. 9. This is a longitudinal section of the same ventricle as in figure 8 , demonstrating the same accessory papillary muscles in another plane (marked with + ). 
J. Ker / International Journal of Cardiology $x x x$ (2011) $x x x-x x x$

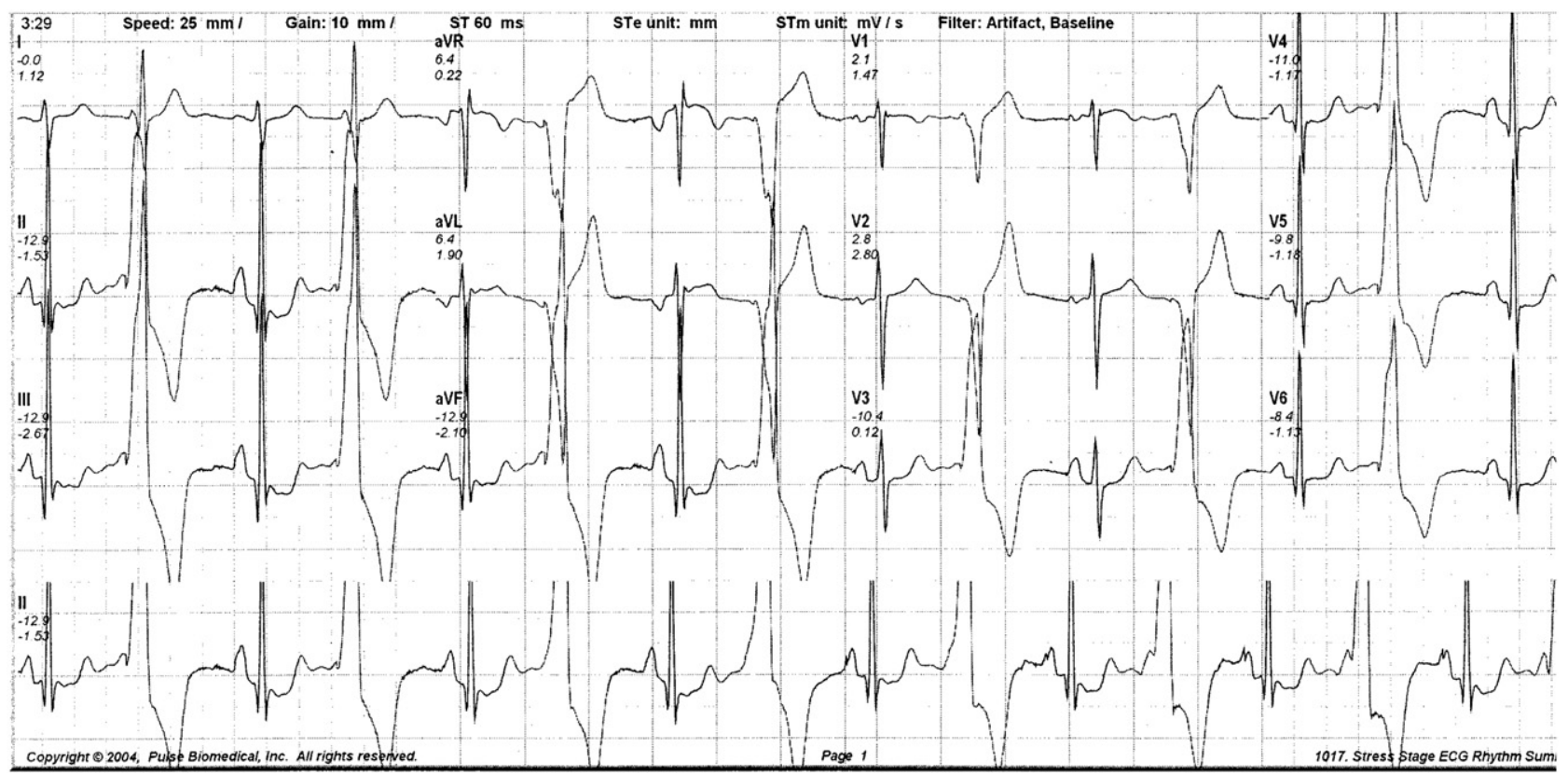

Fig. 10. 12-lead electrocardiogram of a 51-year old Italian woman, presenting with ventricular bigeminy.

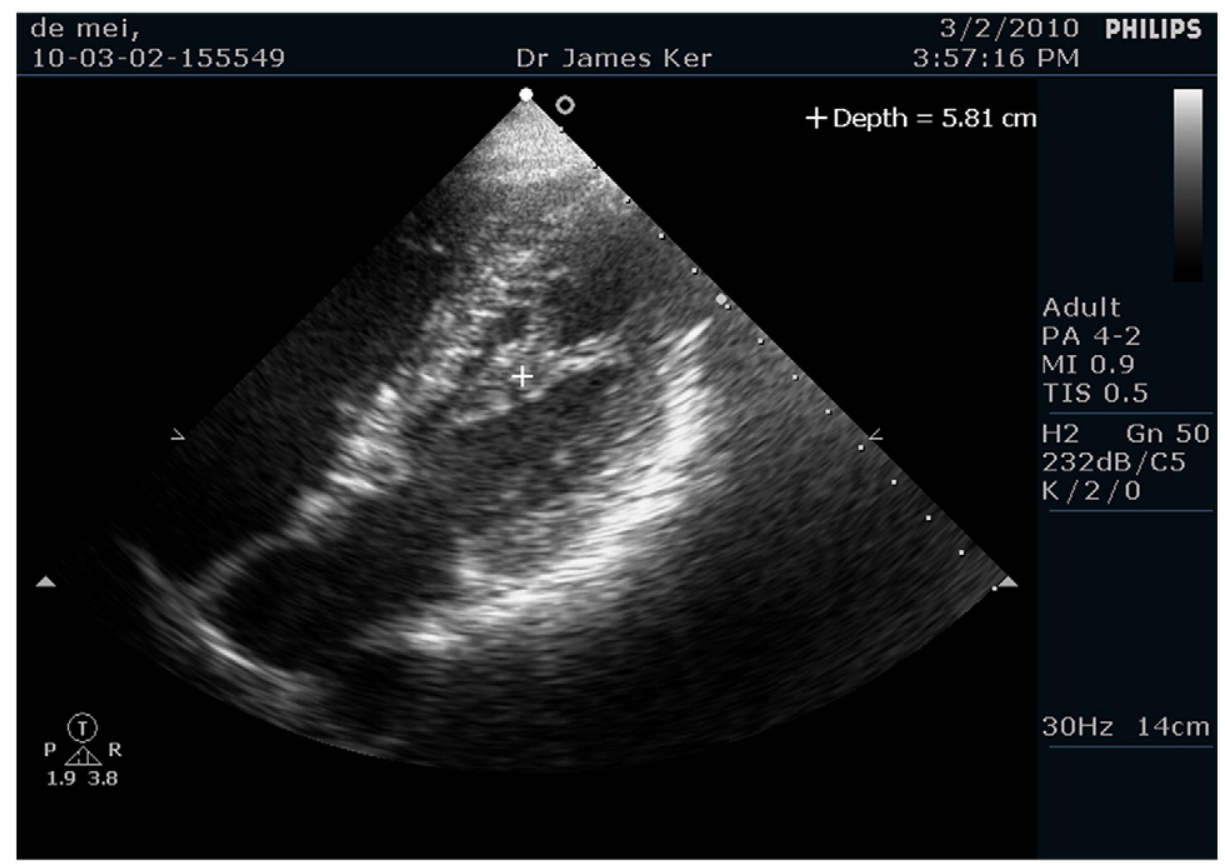

Fig. 11. Echocardiographic image demonstrating the presence of a "bifid" papillary muscle (marked with + ). 